\title{
Ciberactivismo y apropiación social. Un estudio de caso: la insurgencia popular de Oaxaca
}

\author{
Tommaso Gravante \\ Candidato a doctor en Ciencias de la Comunicación (Universidade de Sevilla) \\ Editor del Observatorio Iberoamericano de Ciudadanía Digita \\ t.gravante@gmail.com
}

\begin{abstract}
Resumen Recuperando la experiencia individual en los medios alternativos que han sido determinantes en la organización y en la construcción de la identidad del movimiento popular en la insurrección de Oaxaca en 2006, en la presente comunicación proponemos un breve análisis de la prácticas de ciberactivismo que se han dado a lo largo de la protesta. Con un enfoque desde abajo en el estudio del movimiento popular mismo, exploraremos los modos en los que las prácticas de ciberactivismo influyen en los procesos de empoderamiento y de acción colectiva, introduciendo el análisis de las emociones y de los procesos emotivos tanto a nivel individual como colectivo.
\end{abstract}

Palabras-clave: ciberactivismo, apropiación de las NTIC, medios alternativos, movimientos sociales.

\section{Prácticas de mediactivismo en Red}

6 he revolution will nOt Be televised" cantaba Gil Scott-

1 Heron en los años setenta desde el gueto del Bronx. Sin embargo, en las últimas dos décadas, las nuevas tecnologías de la información y la comunicación han cambiado, sobretodo, ha cambiado la percepción que tienen los movimientos sociales respecto a los medios de comunicación. Hoy, entre los activistas, circula un dicho: una persona detrás de una cámara en una marcha, vale por 1000. Hablando de medios alternativos, significa hablar de prácticas de mediactivismo y en el caso de medios digitales de ciberactivismo. La práctica del ciberactivismo, definida como la apropiación y uso de los medios digitales (Pasquinelli, 2002), ya es parte de una práctica cultural y política que encuentra espacio en el portaequipaje de toda la sociedad "otra", por otro lado, podemos añadir que la práctica de ciberactivismo además de se un fenómeno social y político es también un laboratorio de innovación y experimentación de medios y modelos sociales. En este marco, analizar la práctica del ciberactivismo significa, para nosotros, salir de un enfoque técnico-céntrico y enfocarnos en los procesos de apropiación de los medios y las relaciones que se dan entre el medio y sus usuarios (Atton, 2002), tomando en cuenta su contexto sociocultural y su temática, con el objetivo de explorar los modos en los que la apropiación y uso alternativo de los medios digitales influyen en los procesos de empoderamiento.

En el presente artículo proponemos una metodología de análisis del proceso de apropiación y uso de las nuevas, así como destacamos algunos elementos comunes que hemos encontrado durante dicho análisis. El punto de partida del presente artículo es el trabajo exploratorio de 
investigación llevado a cabo en Oaxaca a lo largo de 2010 dentro del marco de nuestra investigación doctoral, cuyo objetivo principal es el análisis de prácticas sociales y de ciberactivismo en procesos de movilización y cambio social.

\section{Una mirada desde el sur y desde abajo}

Consideramos prioritario investigar la insurrección de Oaxaca desde lo que se considera su esencia: el movimiento mismo (Zibechi, 2007), a través de un enfoque desde abajo y horizontal, sin necesidad de mirar a los de arriba. Para nosotros es fundamental recuperar la experiencia individual de la resistencia, ya que

en la ciencia en general y en las ciencias sociales en particular predomina una visión positivista y estado céntrica que excluye a los sujetos sociales de abajo y solo los convierte en piezas utilizables por los sujetos políticos institucionalizados que con sus acciones siguen reproduciendo la forma Estado y las relaciones sociales capitalistas. (Regalado, 2010, p. 5)

La insurrección de Oaxaca no fue una mera revuelta ni se redujo a una rebelión, fue el proceso de emancipación de una sociedad en movimiento, de una sociedad "otra" (Zibechi, 2007, p. 238) y no fue un episodio aislado. La experiencia de Oaxaca, así como los acontecimientos de las últimas dos décadas en el continente latinoamericano, se insertan en un nuevo ciclo de resistencias protagonizado por subjetividades, organizaciones y luchas que no encajan en las matrices tradicionales sobre "la política" y "lo social" (2007, p. 7).

Para comprender la insurrección popular de Oaxaca es necesario observar los sujetos sociales que hasta ahora no se consideraban sujetos políticos y que se caracterizan por la expansión de su autonomía, la profundización de las prácticas sociales emancipatorias, la construcción de nuevos imaginarios e idearios así como por la transformación radical de las relaciones de poder en un sentido radicalmente democrático. Este aspecto no es solamente metodológico sino también conceptual ya que consideramos, siguiendo a De Certeau (1996), que en la gente ordinaria están presentes movimientos de micro-resistencias que fundan a su vez micro-libertades y que se manifiestan a través de prácticas cotidianas y de una nueva economía moral de la multitud.

A través del análisis de las entrevistas de nuestros informantes pondremos en evidencia cómo la apropiación y uso de los medios de comunicación digitales se convierte en otro modo de hacer política y, por otro lado, cómo la política de los grupos subordinados "se caracteriza por liderazgo informal, de las no élites, de la conversación, de discurso oral y de la resistencia clandestina" (Scott, 2000, p. 217-218). En otras palabras:

se trata de una forma distinta de hacer política, desde lo social-comunitario donde el pensar sin la forma Estado tiene como punto de partida el dejar de reproducirlo y plantearse la necesidad de volver a entramar el tejido social comunitario destrozado por el tipo de relaciones que impone el mercado capitalista. (Regalado, 2007, p. 10)

Dentro de esta episteme resulta evidente que las luchas para una comunicación alternativa se han convertido en luchas políticas porque cuestionan la estructura de poder y plantean una participación activa de la población en los procesos de toma de decisiones.

\section{Apropiación desde la práctica}

El objeto de nuestra investigación no es el medio en sí mismo, sino el proceso de apropiación y uso de las NTIC que definimos como práctica de ciberactivismo. Consideramos las NTIC como una cuestión de mediaciones más que de medios y, por lo tanto, no sólo de conocimiento sino de re-conocimiento, de resistencia y de apropiación desde los usos (MartínBarbero, 1987). Sin duda, la apropiación está vinculada con la naturaleza de los medios técnicos y con la posesión de las habilidades, capacidades y recursos necesarios para producir y decodificar los mensajes transmitidos, pero también está vinculada, de manera más determinante, con los contextos sociales e históricos en los cuales es posible elucidar los modos de apropiación (Thompson, 2002, p. 456). Si tomamos en cuenta las reflexiones de Thompson y las trasladamos a nuestro problema de estudio, la apropiación entonces se da cuando las personas conocen las herramientas, las valoran y aprenden a usarlas para satisfacer sus necesidades e intereses (probablemente las de su grupo social) y le dan sentido de pertenencia. Por este motivo consideramos que el acceso a las NTIC no se reduce a saber usar el ordenador o conectarse a Internet sino que también incluye comprender la tecnología, sus posibilidades (y límites), obtener informaciones útiles y desarrollar una lectura crítica del medio.

Usar y apropiarse de la tecnología implica un proceso no sólo en relación con la herramienta en sí, sino también con el contexto en el cual la tecnología se desarrolla. De esta forma, la herramienta tecnológica se transforma en un objeto relacional y de resignificación de las prácticas diarias de los sujetos 
involucrados en la práctica mediática (Rueda Ramos, 2009), generando, en el proceso de apropiación y re-codificación de las tecnologías, tanto usos diversos como otros nuevos no planteados inicialmente. Para entender el proceso de apropiación es necesario considerar la subjetividad en la construcción social de las experiencias objetivas del usuario (Fuentes, 2006), siendo por este motivo que la apropiación de Internet no debe ser vista como un cúmulo simple de tareas sino que hay que tener en cuenta la situación y la realidad diversa y heterogénea del contexto donde opera el sujeto social. La apropiación entonces no sigue una lógica única sino que se mueve entre diversos niveles según los individuos e intereses mientras que sus significaciones sociales están asociadas directamente, además de a la utilización de las herramientas, a una expansión de su uso y a una conformación de prácticas y procedimientos cotidianos.

Como destaca De Certeau (1996), las mil maneras de hacer/deshacer no designan solamente actividades sino también cambios significativos que se manifiestan en prácticas culturales por lo que, en nuestra opinión, podemos afirmar que tanto la experiencia del conflicto como las experiencias mediáticas por parte de los actores involucrados manifiestan al final un cambio cultural. Es decir, los protagonistas de la práctica mediática $\mathrm{y}$ de las experiencias de resistencia viven un proceso de reelaboración y redefinición de valores, creencias e identidades que los lleva a tomar conciencia de aspectos de la realidad que hasta aquel momento no habían considerado; a cambiar su percepción de la realidad; y, finalmente, a actuar en consecuencia.

El cambio cultural se manifiesta, en parte en prácticas cotidianas (Martín Barbero, 1987; De Certeau, 1996; Scott, 2000; Zibechi, 2006 y 2007), es decir, el proceso de toma de conciencia pasa también a través de las prácticas, siendo estas prácticas las que generan un discurso "otro". Nuestro objetivo será también determinar qué tipos de prácticas pueden señalar un cambio cultural en los actores involucrados, considerando como dimensión explicativa tanto la práctica de ciberactivismo como la experiencia en el conflicto.

\section{Emociones y acción colectiva}

Los diversos niveles de complejidad a la hora de analizar el proceso de apropiación de las NTIC (Marí y Sierra, 2008), junto a los resultados de los análisis del trabajo de campo hecho en Oaxaca a lo largo de 2010, nos han llevado a considerar el fuerte impacto emotivo que caracteriza estas experiencias de conflicto. Nuestro objetivo no es comprender qué son las emociones y qué efecto tienen en el individuo, análisis que dejamos a la sociología de las emociones y a la psicología, sino considerar la dimensión emotiva en los diferentes procesos que se dan a lo largo de la experiencia mediática (motivación a la acción, motivación al aprendizaje, procesos de autoestima, nuevas relaciones y nuevos proyectos, desarrollo de un concepto de una comunicación comunitaria etc.), y observar cómo las emociones interactúan con nuestros procesos cognitivos y cómo nos motivan en la acción política (Goodwin, Jasper y Polleta 2001).

La introducción de esta dimensión subjetiva, poco o nada habitual en los estudios de comunicación pese a su relevancia, nos permite una investigación más profunda de la motivación de los individuos, resultando un análisis más rico y más profundo del proceso de apropiación de las nuevas tecnologías.

Coincidimos con Goodwin y Jasper (2004) en que las emociones están construidas por significados sociales compartidos y no por estados psicológicos automáticos e inconscientes. En relación con la noción de la motivación a la acción, Ron Aminzade y Doug McAdam (2001) comentan que las emociones y los procesos emocionales cuentan con una gran capacidad explicativa tanto a nivel individual como colectivo. A nivel individual las emociones motivan el activismo y permiten entender por qué los individuos deciden involucrarse incluso cuando los costes de la movilización superan los beneficios (Aminzade y McAdam, 2001, p. 17; Goodwin, Jasper y Polletta, 2001, p. 5-9), mientras que a nivel colectivo crearían el ambiente favorable para el desarrollo de la movilización (Aminzade y McAdam, 2001). Entrando más en nuestro ámbito de análisis, las emociones adquieren un papel importante en la motivación a la acción porque determinan la relación de los protagonistas del conflicto con la apropiación y el uso de las nuevas tecnologías. La motivación para la acción es además motivada por sentimientos como la indignación, el sentimiento de injusticia por no haber sido incluido en el proceso de toma de decisiones, así como por la rabia o la esperanza. A eso se añade el orgullo que va creciendo durante el proceso de movilización que motiva aún más a los participantes y que fortalece los vínculos entre los miembros tanto de la experiencia mediática como de la comunidad involucrada en la lucha. Nuestro trabajo pretende contribuir a la observación y estudio de la interacción de las emociones con otras dinámicas culturales, contribuyendo al reto empírico de enriquecer el conocimiento en esta dirección, sin olvidar la interacción de las mismas con dinámicas organizacionales y estratégicas, ya que las "emociones son centrales en todo estos aspectos" (Goodwin, Jasper y Polletta, 2001, p. 9).

Parte del material conseguido a través de las entrevistas son narraciones de acontecimientos y vivencias en las que analizaremos el papel de las emociones y los procesos que llevan al cambio. Coincidimos con 
Barbara Poggio en que "el cuento es vehículo de una verdad, la del sujeto, de su manera de mirar a la vida, de asociarle significados, valores, emociones" (2009, p. 12), ya que:

el storytelling se presenta como un proceso estrictamente relacionado con el ámbito emocional (...) y es sólo solicitando y moviendo los hilos emocionales de los destinatarios que las historias pueden trasmitir significados y normas culturales. (2009, p. 103)

El análisis de las narraciones presentes en nuestras entrevistas se convierte así en una herramienta coherente con el enfoque y el propósito de la investigación, permitiendo acceder "a la riqueza y a la profundidad del saber ideográfico consiguiendo así un más profundo acceso al mundo social" (Poggio, 2009 , p. 17). Vamos ahora a describir brevemente el contexto en que se inserta nuestra investigación y las causas del estadillo del conflicto.

\section{5. "Si somos minoría por qué la policía"”}

El Estado de Oaxaca es un escenario de paradojas: extremadamente rico en recursos naturales y culturales, pero muy pobre en términos económicos y con una alta desigualdad social, junto con Chiapas y Guerrero, es uno de los estados más pobres y rezagados de México (Coneval, 2007a y 2007b). El despojo de las tierras comunales, facilitado por la reforma del Artículo 27 de la Constitución en 1992 (Olivera, 2005), incrementó exponencialmente los conflictos agrarios en todo el país (SRA, 2010), y fue la migración forzosa hacia las ciudades - y a los EE.UU: - de una amplia franja de la población rural.

En este contexto económico y social el Estado de Oaxaca recibe la histórica alternancia en las elecciones presidenciales del año 2000, en que la llegada a la presidencia del candidato del Partido Acción Nacional, Vicente Fox, puso fin a la larga etapa de dominio y hegemonía del régimen corporativista priísta (Partido Revolucionario Institucional). A pesar del cambio nacional en Oaxaca, como en otras regiones, se profundizaron los rasgos del viejo régimen priísta: de echo, la elección de Vicente Fox relajó los controles del presidente sobre los gobernadores y permitió que éstos actuaran sin frenos, como ocurrió en Oaxaca en las legislaturas de José Murat (1998-2004) y de Ulises Ruiz (2004-2010).
El 14 de junio de 2006 hay el estadillo de la insurrección popular. Bajo los ordenes del Gobernador Ulises Ruiz, que quiere acabar con toda forma de disenso en Oaxaca, la policía desalojó de violentamente una acampada del sindicado de maestros (SNTE) de en la plaza principal de la ciudad. ${ }^{2}$ Las protestas de la ciudadanía en contra de la política autoritaria del gobernador cobró en pocos días la dimensión de una amplia y profunda insurrección popular, con un alto sentido antiautoritario. Bajo la consigna común de “¡Ya cayó, ya cayó! U Ulises, ya cayó!”, la mayoría de la población se apropió de la ciudad y las colonias, y se auto-organizó instituyendo sus propias barricadas de defensa, sus espacios de discusión y comunicación así como sus propios modos de construir formas de vida. Los medios de comunicación alternativos tuvieron mucha importancia en el movimiento popular. Tanto la apropiación y uso de las nuevas tecnologías de la información como la toma de las emisoras de radios y televisión por parte de simples ciudadanos, fueron determinantes en la organización y en la construcción de la identidad del movimiento popular. Estos medios no eran únicamente medios alternativos de comunicación e información sino el movimiento mismo hablando y escuchándose (Esteva, Valencia y Venagas, 2008, p. 105).

En pocos meses desde el comienzo del conflicto se crearon más de veinte páginas web que contribuyeron a romper el cerco mediático de los medios oficiales y cautivar la atención internacional. Se tomaron decenas de radios comerciales y, durante un mes, más de 300 mujeres tomaron y gestionaron las instalaciones estatales de radio y televisión (Canal 9). Disponer de medios propios y reflexionar sobre un posible proceso de democratización de la comunicación fue una prerrogativa del movimiento a lo largo de todo el conflicto (Appo, 2006 y 2007), como de explorar las modalidades de una comunicación "otra", es decir de "una nueva comunicación para una nueva sociedad» (De Castro, 2010, p. 32). Pero, a las demandas de dignidad, de cambio social y político, de justicia que llegaban desde abajo, el Gobernador Ulises Ruiz respondió con la política de la violencia y de la represión brutal, dejando en meno de seis meses un saldo total de 23 muertos, 600 detenidos sin orden de aprehensión y flagrancia y la desaparición forzada de 200 ciudadanos (Cciodh, 2007). La política del terror y la violencia extrema ejercida por los cuerpos policiales autorizados por Ulises Ruiz causó la paulatina retirada de la base popular del movimiento. Después de enero de 2007, el movimiento de protesta siguió en semi-clandestinidad en un clima de represión militar

1. Uno de los tantos murales realizado en la ciudad de Oaxaca durante el conflicto.

2. El sindicado protestaba para una mejoría de sus condiciones laborales. La protesta se llevaba a cabo desde más de una década en el mes de mayo. 
por parte del gobernador Ulises Ruiz, que terminó su mandato en diciembre de 2010.

\section{Algunos análisis de las entrevistas}

En nuestra investigación las experiencias ${ }^{3}$ que hemos elegido surgieron desde la iniciativa ciudadana a la luz de la insurgencia de 2006 y han tenido un papel mediático y simbólico relevante en el movimiento popular, algunas de ellas todavía continua su actividad. Para salir desde un enfoque mediocéntrico y comprender las dinámicas de apropiación y apreciar el cambio cultural vivido por los entrevistados en sus experiencias, hemos considerado en nuestra muestra, además de experiencias "puras" de ciberactivismo, otras experiencias de mediactivismo como radio y televisión que se desarrollaron a lo largo del conflicto.

En todas las experiencias analizadas, el componente emotivo tiene un papel fundamental en la motivación a la acción. Los sentimientos de indignación y rabia a causa del violento desalojo del 14 de junio de 2006 fueron uno de los elementos detonantes en el proceso inicial de apropiación:

"los que nos agarró para pensar fue la represión.” (E3)

“[...] y aparte también el coraje, porqué sientes esas impotencia, porque no hay posibilidades.” (E1)

"Oaxaca Libre nació formalmente en la madrugada del 14 de junio del 2006, día del desalojo del plantón." (E3)

Los entrevistados evidencian cómo el desalojo violento de los maestros se suma a un discurso oculto (Scott, 2000):

"por qué sientes esas impotencia porque no hay las oportunidades de trabajos, para estudiar, no hay oportunidades [...] ese malcontento se suma a la pobreza. Y ya no se aguanta [...] y todo se va sumando." (E1)

La indignación y a la rabia son, entre otras cosas, las emociones que llevaron a crear un medio alternativo de comunicación, para:

"[...] decirle a la gente que se levante, [...] levantar los compas (compañeros)." (E7)
Y para poder seguir a:

"[...] denunciar las graves violaciones a derechos humanos que se estaban suscitando en Oaxaca, darle voz a los sin voz." (E4)

Otro elemento clave fue que los medios comerciales no representaban la realidad vivida por lo protagonistas:

"(los medios oficiales) no la decían o la cambiaban (la información) o utilizaban la acción que se estaba haciendo para criminalizar la protesta social. Esto fue una motivación más". (E1)

Además de la deslegitimación del movimiento popular y la manipulación de la información:

“(Ulises Ruiz ) tenía los medios comerciales pero [...] no podía seguir con esta campaña de desprestigio hacia el movimiento, hacia los maestros; cuando nosotras sabíamos la realidad y las estábamos viviendo. [...]". (E9)

"Lamentablemente la mayoría de los medios oficiales como su nombre lo dice son oficiales por lo que la voz de los maestros de la APPO no era escuchada o como ya comenté si los tomaban en cuenta la mayoría lo hacía para descalificar el Movimiento social y magisterial [...]." (E5)

Esto llevó las personas a encontrar nuevas herramientas de comunicación para el movimiento mismo:

"El objetivo de inicio fue crear un medio alternativo, paralelo a lo que ya existían, donde se diera a conocer la información de lo que acontecía en Oaxaca y que era omitida en otros medios, sin intenciones mercantilistas." (E6)

Ninguno de los entrevistados había tenido experiencias anteriores:

“[...] yo no sabía nada sobre radio, sobre el lenguaje radiofónico, todo lo que implica hacer radio, medio de comunicación." (E7)

“[...] (nosotras) ya utilizábamos Internet, pero no sabíamos cómo administrar una página, ni sabíamos de plantillas de páginas web.” (E5)

Y aunque las dificultades técnicas fueron muchas: 
“[...] en varias ocasiones no sabíamos cómo subir notas sin que se desacomodaran los textos, no sabíamos cómo subir imágenes, cómo crear secciones o módulos, cómo manejar los comentarios, audio, textos en pdf, o por qué algunas veces la página marcaba error etc." (E6)

Todas fueron superadas compartiendo el conocimiento con quien ya poseía una alta alfabetización digital, generalmente gente externa al proyecto:

"(las dificultades) la superamos cuando el amigo que creó la página nos explicó el por qué sucede y qué debemos hacer para que lo anterior no ocurra." (E5)

"[... ] Coincidió, también, que unos amigos del Centro de Medio Libre (del D.F.) y otros compas vinieron a dar unos talleres de software libre y allí fue donde aprendí más y me fui interesando (al software libre)." (E7)

"Un compañero vio el blog y le gustó lo que se escribía por lo que aceptó ayudarnos, se unió a nosotros y construyó la página a la que más tarde nos mudamos." (E6)

O buscado en la misma red de Internet:

“también aquí (en Oaxaca) andaban otros compas que se quedaron y si tenía dudas le preguntaba cómo se hace esto... esto y lo otro o yo lo buscaba en Internet." (E7)

“Siempre buscando soluciones, [...] en Internet." (E6)

También en el uso de las radios y en el canal de televisión tomados, los problemas técnicos se superaron poniendo en común los conocimientos; así, en pocas horas, las radios y la televisión estaban en el aire, sin ningún tipo de intimidación por parte de los participantes:

"[...] desde que nos conectaron allá y pudimos salir al aire, una compañera tomó el micrófono y de allá se fue una larga fila de mujeres que querían también manifestar lo que sentían [...].” (E9)

Para todas las experiencias, la mayor dificultad residió en los recursos económicos, sobre todo en el caso de los portales web: el coste de un dominio, de un servidor con alta capacidad de almacenamiento y transferencia, obligaron a algunas experiencias a optar por plataformas comerciales como Blogger o a limitar el uso de las herramientas multimedia.

Haciendo un breve análisis técnico de los medios digitales resulta que todos los portales web se realizaron con CMS (Content Manager System); bitácoras que se manejan directamente con el servidor remo- to, sin la necesidad de instalar ningún software en el ordenador; la gran mayoría de las experiencias de ciberactivismo optaron por bitácoras open source. Más de la mitad de las experiencias estudiadas instalaron en sus ordenadores un sistema operativo free software.

Con esta premisa, retomando el análisis de las entrevistas, resulta que todos los entrevistados sobre las experiencias de medios digitales expresan interés por el software libre y su filosofía:

“(cuando) aprendí lo básico, llegué a mi casa, instalé mi compu (ordenador) le quité lo que tenia, el Windows, le puse Linux y empecé a explorar. Así fue aprendiendo." (E7)

Interesante es observar como los entrevistados se apropian, además de las herramientas técnicas, también de las prácticas que caracterizan el movimiento de software libre:

"sentimos cómo dos movimientos que se articulaban; por un lado el periodismo libre, refiriéndome a la organización horizontal y por otro el software libre, ambos con un compromiso social donde la teoría no se desvincula de la práctica." (E5)

A nivel de recursos en los portales web el grupo inicial fue muy reducido, pero a lo largo del conflicto en todas las experiencias hubo un aporte externo de voluntarios, que permitió ampliar la plantilla:

"Después creamos un equipos de reporteros gráficos y un equipos de reporteros que escribían lo que estaba pasando en la calle, [...] lo que hace la gente." (E3)

"Luego compañeros se acercaron y con sus textos comenzaron a aportar mucho al proyecto.” (E5)

En los diferentes medios analizados no existió una línea editorial definida a priori, la tendencia era acudir a la información cotidiana.

“sobre qué contenido iba en la página hemos elegido relacionarnos con el cotidiano para ver qué informaciones interesaban a la gente.” (E5)

"Nos reunimos y empezamos a mencionar y escribir qué temáticas nos gustaría incluir, hicimos también una encuesta en la página y le preguntábamos a la gente que conocíamos qué temas les gustaría leer, también comenzamos a observar lo aparentemente cotidiano." (E6)

La represión continua y la necesidad por parte de la gente de estar continuamente informada influyeron en los tiempos y en los modos de uso del medio: 
"la información era mucha sobre el movimiento, porque la represión todavía estaba. No había chance de pensar en otra cosa, no había el tiempo de pensar en otro tipo de programación más ligero, con buen contenido. Porque la represión todavía estaba. Entonces no había tiempo de pensar en un programita que era más digerible pero que tenia información [...].” (E7)

Finalmente, a nivel organizativo y decisional todos los medios alternativos se caracterizaron por tener una estructura horizontal y asamblearia:

“(el proyecto) se constituyó sobre una organización horizontal y asamblearia.”. (E5)

Haciendo una evaluación de las experiencias, todos los entrevistados reconocen haber vivido un cambio importante gracias al proceso de apropiación y uso de los medios alternativos de comunicación:

“(la experiencia del blog) me impulsó a seguir denunciando, vi la importancia que los medios alternativos estábamos teniendo en el conflicto social y la magnitud de lo que nuestro trabajo representaba para ellos, muchas veces la gente que salía a protestar o a denunciar me decía «si tu estas aquí, sabemos que todo lo grabarás y que entonces todos lo conocerán», eso me impulsó siempre a seguir." (E4)

Como se puede apreciar, el sentimiento de orgullo que va creciendo durante el proceso de movilización motiva aún más a los participantes y fortalece los vínculos entre los miembros tanto de la experiencia mediática como de la comunidad involucrada en la lucha.

Mientras, el cambio debido al proceso de apropiación del medio digital en los entrevistados se manifiesta en diferentes prácticas, como el desarrollo de nuevas relaciones sociales y personales:

“[...] madurar en el ámbito personal, a apropiarse de herramientas al servicio del periodismo libre, a crear lazos de amistad etc. [...]." (E6)

“Asimismo, la página nos brindó la oportunidad, por las personas que conocimos en foros y por medio de entrevistas, de conocer muchos pueblos de Oaxaca y alternativas de vida, no sólo políticas, sino ecológicas, de comunicación y económicas."

O fortalecer la autoestima y en la superación de barreras ideológicas y culturales:

"como mujeres esta experiencia ha sido enriquecedora. Yo nunca pensé que fuéramos parte de un colectivo y enterarme de muchas cosas... saber cosa es la violencia contra la mujer y a lo mejor lo hemos estado viviendo y no nos hemos dado cuenta. El hecho de reunirnos puras mujeres nos ha llevado, a mi en lo personal, a un panorama totalmente diferente." (E10)

En un fortalecimiento de la desconfianza hacia los medios oficiales de comunicación, que se manifiesta en una reelaboración de la idea de comunicación y de medio de información:

"nos dimos cuenta que sólo si se pueden contar historias se puede tener sentido en hacer un medio. Si introduces a la gente [...] haces el periodismo más creativo y más narrativo y esto rompe con el objetivismo del periodismo convencional [...] hablar de la gente como una persona real y hablar del pueblo como una comunidad que se organiza, que tiene conflictos etc. Creo que es necesario darle esta parte más humana en la nota (de prensa)". (E3)

O en pensar en otro tipo de periodismo:

"hacer periodismo mirando a la gente del pueblo, no a los políticos de tiempo completo, te da la oportunidad de conocer miles de visiones del mundo, que generalmente son omitidas en los medios comerciales. Y mostrar esas visiones es generar otro tipo de información." (E5)

Finalmente, el proceso de aprendizaje social es inseparable de las experiencias vividas a lo largo de la insurgencia:

"nos dejó una lección muy grande el movimiento; (como) el hecho que sólo organizadas podemos conseguir muchas cosas, de hecho el colectivo Mujeres Nuevas es fruto de este movimiento.” (E9)

"Creo que el 2006 unió a las mujeres y nos hemos vueltos más participativas, más combativas, más solidarias." (E11)

"Los más importante fue la unidad y conocernos. Yo por ejemplo no conocía bien mis vecinos y en las barricadas conocí más a mis vecinos. El vecino de atrás es arquitecto....o la señora de la tienda y era solamente "buenos días". Y ahora no, paso a la tienda y le digo “¿cómo estas?”. Hace poco se murió el esposo de la señora de la tienda y fuimos a verlos, allí llegaron todos los compas .... allí (en la barricada de la colonia) se creó una comunidad, se crearon otras formas de relación, esto creo que es lo más chingón (importante), las formas de relacionarnos y estar juntos." (E7)

Al margen de esos análisis queremos también destacar brevemente algunas consideraciones de los 
entrevistados en las experiencias de ciberactivismo sobre el uso de los Social Networks.

Twitter resultó ser el canal social más implementado en las páginas web. Los entrevistados muestran un cambio de mentalidad al hacer una nota (140 caracteres) y tener la posibilidad de difundir la información de forma más rápida que a través de la misma web:

“creo que Twitter está rompiendo con todas las barreras de información".

Mientras que Facebook fue poco utilizada puesto que se veía como una herramienta social más apta para asuntos personales. Otro instrumento social utilizada a menudo fue la plataforma comercial Youtube:

"[...] usamos el Youtube para subir videos y luego enlazarlos a la página, fue muy útil pues ahí se alojaban los documentales o entrevistas que hacíamos." (E5)

El uso de la plataforma gratuita Youtube permitió poder subir a la red una enorme cantidad de videos que testimoniaban las violencias del cuerpo policial y la represión del movimiento, sin afectar a los escasos recursos económicos de mantenimiento de las páginas web.

Un dato interesante es el uso de los podcasting por parte de todas los sujetos entrevistados. Esto ha permitido no solamente realizar píldoras radiofónicas, sino alojar material de audio proveniente de radios analógicas ubicadas tanto en la ciudad como en el resto del estado:

\footnotetext{
"los podcast son una sección en la cual pueden descargar los compañeros de las radios comunitarias algún material que quieran ocupar para sus transmisiones, o bien personas que quieran escuchar el audio en otro momento.” (E5)
}

Finalmente, el acercamiento al software libre permitió sucesivamente la formación de una comunidad activa hacker en Oaxaca, que en 2008 se sumará al Festival de Instalaciones de Software Libre en Latinoamérica (FLISOL) y en 2010 colaborará en la realización del Hacker Meeting de México en la misma ciudad de Oaxaca.

\section{Primeras conclusiones}

En estos primeros análisis sobre la prácticas de ciberactivismo relacionado con la acción colectiva en una protesta hemos podido apreciar tanto los elementos que han caracterizado el proceso de apropiación de las nuevas tecnologías, como el cambio cultural vi- vido por parte de los participantes en las experiencias de medios alternativos de comunicación y cómo esto se manifiesta en prácticas cotidianas. Uno de los elementos principales que determinan la motivación a la acción por parte de los entrevistados son las emociones que siguen al violento desalojo del plantón de los maestros el 14 de julio de 2006 y que nos permiten entender por qué los individuos deciden involucrarse. El sentido de impotencia, de injusticia y rabia son, en nuestro caso, emociones compartidas socialmente que juegan un papel fundamental en las experiencias analizadas, tanto a nivel individual como a nivel colectivo. Estos sentimientos compartidos se alimentaron de un malestar general que remitía a un profundo discurso oculto presente en la sociedad oaxaqueña. Mientras, la desinformación practicada por los medios oficiales alimentó tanto la necesidad como la voluntad de apropiarse de los medios de comunicación, con el objetivo de "narrar" la realidad vivida y "dar voz a la gente".

Analizando la dimensión técnica, se observa que la falta de conocimientos técnicos es del todo influyente en la apropiación y uso del medio. Los diferentes problemas surgidos en este ámbito a lo largo de la experiencia mediática (tanto digital como analógica) se resolvieron compartiendo el conocimiento con personas externas pero afines al proyecto. Asimismo en las experiencias de ciberactivismo se manifiesta una relación entre la falta de recursos y de conocimiento y el software libre y su filosofía. La relación entre software libre y práctica de mediactivismo no se limita solamente al uso de aplicaciones no propietarias, sino que implica considerar el conocimiento y la comunicación como un bien común y, por ello, sujeto a ser compartido sin restricciones.

Desde una perspectiva organizativa y decisoria, los testimonios de los medios digitales asumieron una organización horizontal y democrática, reflejando en cierta medida la estructura reticular y horizontal de Internet. Cada experiencia de ciberactivismo ha constituido un nodo autónomo enlazado, a través de uniones horizontales, a otras experiencias sociales heterogéneas (colectivos de vecinos, organizaciones sociales, otros medios alternativos de comunicación etc.), dando lugar a una red social de experiencias. El proceso de fortalecimiento de la red social creada no pasa por un proceso de unión de las experiencias o de una mayor relación entre ellas, sino por un proceso de crecimiento autónomo de las mismas.

La experiencia del conflicto se entrelaza de forma indisoluble con la práctica ciberactivismo. En los entrevistados, el proceso de toma de conciencia a través de la experiencia de apropiación de las NTIC está relacionado con la experiencia personal que el sujeto vive en el conflicto. En esta línea, la reflexión sobre la efectiva posibilidad de desarrollar "otra" comunicación está vinculada a la necesidad de narrar la vida de 
la gente "común y corriente". Podemos concluir que el conflicto social además de ser un punto de ruptura con el orden constituido es un laboratorio necesario para el cambio social, en el que la práctica de ciberactivismo contribuye a generar espacios sociales para una cultura disidente.

\section{Referências}

AMINZADE, Ron; MCADAM, Doug. Emotions and Contentious Politics. En: AMINZADE, Ron et al. Silence and Voice in Contentious Politics. Cambridge: Cambridge University Press, 2001. p. 14-50.

APPO. Declaración política de la constitución formal de la Asamblea Popular de los Pueblos de Oaxaca. Oaxaca. Mimeografado, 2006.

APPO. Acuerdos de la Primera Asamblea Estatal de la Asamblea Popular de los Pueblos de Oaxaca. Oaxaca. Mimeografado, 2007.

ATTON, Chris. Alternative Media. London: Sage Publications, 2002.

CCIODH. Comisión Civil Internacional de Observación por los Derechos Humanos. Informe sobre los hechos en Oaxaca. V Visita: del16 de diciembre de 2006 al 20 de enero 2007. México: CCIODH, 2007.

CONEVAL. Consejo Nacional de Evaluación de la Política de Desarrollo Social. Los mapas de la pobreza en México. México: CONEVAL, 2007a.

CONEVAL. Validación estadística de las estimaciones de la incidencia de pobreza estatal y municipal por niveles de ingreso. México: CONEVAL, 2007b.

DE CASTRO, Sergio. Oaxaca: más allá de la insurrección. Crónica de un movimiento de movimientos (2006-2007). Oaxaca: Ediciones ¡Basta!, 2010.

DE CERTEAU, Michel. La invención de lo cotidiano. Artes de hacer, v. I. México: UIA-Iteso, 1996.

ESTEVA, Gustavo; VALENCIA, Rubén; VENAGAS, David. Cuando hasta las piedras se levantan. Buenos Aires: Antropofagia, 2008.

GOODWIN Jeff; JASPER, James; POLLETTA, Francesca. Passionate Politics. Emotions and Social Movements. Chicago: The University of Chicago Press, 2001.

GOODWIN, Jeff; JASPER, James (Ed.). Rethinking Social Movements. Structure, Meaning and Emotion. Maryland, USA: Rowman \& Littlefield Publishers, 2004.

FUENTES, María Cristina. El cibercafé popular en México y la formación no convencional. Congreso Cibersociedad, 2006. Disponible en: <http://www.cibersociedad.net/ congres2006/gts/comunicacio.php?id=751>. Acceso el: 20/3/2011.

HAMELINK, Cees. Language and the Right to Comunícate. En Media Development, v. XLVI, 4/1999.

KELLY, Janice; BARSADE, Sigal. Mood and Emotions in Small Groups and Work Teams. En: Organizational Behavior \& Human Decision Processes, v. 1, n 86, Issue 1, September. p. 99-130, 2001.

MARÍ SÁEZ, Víctor Manuel; SIERRA CABALLERO,
Francisco. Capital informacional y apropiación social de las nuevas tecnologías. Las redes críticas de empoderamiento local en la Sociedad Europea de la Información. Telos: Cuadernos de comunicación e innovación, $n^{\circ} 74$, p. 126133, 2008.

MARTÍN-BARBERO, Jesús. De los medios a las mediaciones. Comunicación, cultura y hegemonía. Barcelona: Editorial Gustavo Gili, S.A., 1987.

OLIVERA, Gilberto. La reforma al artículo 27 constitucional y la incorporación de las tierras ejidales al mercado legal de suelo urbano en México. Scripta Nova, v. IX, no 194 (33), 2005. Disponible en: <http://www.ub.es/ geocrit/sn/sn-194-33.htm>. Acceso el: 30/7/2010.

PASQUINELLI, Matteo (Coord.). Media Activism. Strategie e pratiche della comunicazione indipendente. Roma: Derive Approdi, 2002.

POGGIO, Barbara. Mi racconti una storia? Il metodo narrativo nelle scienze sociali. Roma: Carocci, 2009.

RUEDA RAMOS, Erika. Los adultos y la apropiación de tecnología. Un primer acercamiento. Mediaciones Sociales. Revista de Ciencias Sociales y de la Comunicación, $\mathrm{n}^{\circ}$ 4, $1^{\circ}$ sem., p. 329-354. ISSN electrónico: 19890494, 2009. Disponible en: <http://www.ucm.es/info/ mediars/MediacioneS4/Indice/indice.html>. Acceso el: 15/0/2010.

REGALADO, Jorge et al. Los movimientos sociales y el poder. La otra campaña y la coyuntura política mexicana. Guadalajara, México: Taller editorial La Casa del mago, 2007.

REGALADO, Jorge. Los movimientos sociales en México. La vía autonomista y comunitaria. Ponencia presentada en el encuentro de REMISOC, Nodo de Occidente, el 7 de octubre de 2010 [En línea]. Disponible en: <http:// www.remisoc.org. $\mathrm{mx} /$ index.php?option $=$ com_rokdownl oads\&view $=$ file $\&$ Itemid $=102 \&$ id $=96$ : ponencia-de-jorge regalado $>$. Acceso el: 30/5/2011.

SCOTT, James. Los dominados y el arte de la resistencia. Discursos ocultos. México, DF: Ediciones Era, 2000.

SRA. Secretaria de la Reforma Agraria. Comunicado de prensa $n^{\circ}$ 014, 5 febrero de 2010. México: SRA, 2010.

THOMPSON, John B. Ideología y cultura moderna: teoría crítica social en la era de la comunicación de masas. México: UAM-Xochimilco, 2002.

ZIBECHI, Raúl. Dispersar el poder. Los movimientos como poderes antiestatales. Buenos Aires: Tinta Limón, 2006.

ZIBECHI, Raúl. Autonomías y emancipaciones. América Latina en movimiento. Lima: Fondo Editorial de la Facultad de Ciencias Sociales y UNMSM, 2007. 


\title{
Ciberativismo e apropriação social. Um estudo de caso: a insurgência
} popular de Oaxaca

\section{Resumo}

A presente pesquisa analisa a apropriação social da Internet e a utilização de meios alternativos de comunicação por movimentos, grupos e organizações de resistência em mobilização popular ocorrida em 2006 em Oaxaca, no México.

Palavras-chave: ciberactivismo; novos meios; ativismo na internet; movimentos sociais; comunicação alternativa.

\section{Cyberactivism and social appropriation. A case study: Oaxaca popular insurgency}

\begin{abstract}
This article analyses common elements found on the internet activism practice, defined as communication digital media use and appropriation in a social conflict contest. Its starting point is based on interviews carried out through cyberactivism member's experiences that were decisive in popular movement identity construction and organization during Oaxaca popular uprising in 2006.
\end{abstract}

Key words: cyberactivism, appropriation and use of digital media, social movements, social networks.

Data de recebimento do artigo: 05/11/2011

Data de aprovação do artigo: 29/01/2012 